\title{
Influence of a Cosmetic Company's Eco-Friendly Activities on Consumers' Purchase Intention through the Mediating Effects of Perceived Image
}

Yoo-Jin Oh

Department of Health and Beauty, Dongduk Women's University, Seoul, Korea

Corresponding author: Yoo-Jin Oh, Department of Health and Beauty, Dongduk Women's University, 60, 13-gil, Hwarang-ro , Seungbuk-gu, Seoul 02748, Korea Tel.: +82 29404107 Fax: +82 29404109

Email: mighty0504@gmail.com

Received March 31, 2020

Revised April 24, 2020

Accepted May 15, 2020

Published June 30, 2020

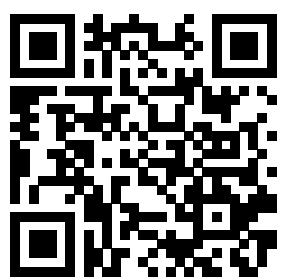

\begin{abstract}
Purpose: The purpose of this study is to investigate the impact of a cosmetic company's eco-friendly activities on purchase intention for cosmetics through the mediating effects of perceived image. Methods: To accomplish this objective, a literature review and a questionnaire survey were performed. Random sampling was conducted in September 2019 in four cosmetics Seoul and Kyunggi area stores. Out of 400 questionnaires, 308 were analyzed using PASW Statistics by Statistical Package for the Social Sciences (SPSS) 19.0 and AMOS 19.0 software. The frequency, reliability, validity were measured and the root mean square error of approximation, root mean square residual, goodness-of-fit index, normed fit index, Tucker-Lewis index, comparative fit index, and Sobel testing were conducted. The Cronbach's alpha value was measured at 0.748 and 0.801 . Results: The results of Sobel testing verification for the intermediate path was $3.661(p<0.05)$ on basal material affecting customers' purchase intention for cosmetics mediating the effect of perceived image, $2.983(p<0.05)$ for the manufacturing process affecting purchase intention for cosmetics mediating the effect of perceived image, 2.010 $(p<0.05)$ for distribution affecting the purchase intention for cosmetics mediating the effect of perceived image, $0.964(p<0.001)$ for packaging affecting purchase intention for cosmetics mediating the effect of perceived image, and $0.825(p<0.001)$ for recycling affecting the purchase intention for cosmetics mediating the effect of perceived image. Conclusion: Cosmetic companies should persist with their ecofriendly activities for forming their perceived image with consumers. It can be helpful to increase their eco-friendly image and to increase customers' purchasing intention for cosmetics.
\end{abstract}

Keywords: Affecting factors, Cosmetics, Eco-friendly activity, Perceived image, Purchase intention

\section{Introduction}

\section{1. 연구의 필요성 및 목적}

건강에 대한 관심이 높아지면서 자연과 함께 심신의 안정을 꾀하 고 삶의 질을 개선하고자 하는 친환경 트렌드가 최근 소비자들의 라 이프 스타일로 자리잡고 있다(Jang \& Yoo, 2012). 이와 같은 소비 자들의 끊임없는 욕구 변화는 기업의 차별화된 브랜드 이미지를 요 구하고 있다(Lee et al, , 2017). 이에 소비자들의 욕구를 만족시키 고, 브랜드 이미지를 향상시킬 수 있는 기업의 활동이 여러 분야에
서 일어나고 있다(Park et al., 2015). 최근 과학의 발달로 인해 기 업간의 기술 격차가 날로 줄어듦에 따라 소비자 트렌드에 부합하는 기업의 브랜드 이미지는 소비자의 선택에 중요한 요인이 되고 있는 데(Lee, 2016), 과거 제품의 기능, 포장 위주의 이성 마케팅을 대상 으로 한 선택에서 벗어나 기업의 이미지와 가치 중심의 감성 마케 팅이 중요시 되고 있다(Jeon \& Li, 2015). 이러한 시장 변화는 화장 품 업계도 예외가 아니어서 자연과 건강을 접목시킨 친환경 활동의 화장품 브랜드 이미지가 강조되고 있다(Kim et al., 2016a). 화장 품 기업에서의 친환경 활동이란 자연에서 가져온 원료를 사용하거 
나(Jeong \& Yoo, 2018), 가공과정을 최소화(Kim et al., 2018)하고, 포장 및 유통, 재순환을 통해 자연의 일부인 인간이 자연과 함께 공 생하고 자연을 보호하면서 소비활동을 하는 일련의 과정을 의미한 다(Kim et al., 2018). 먼저 원료 면에서 재배과정부터 제품 생산에 이르기까지 농약, 비료 등의 화학 성분을 배제한 유기농 원료 등 가 공되지 않은 자연에서 채취한 원료로 식물성분, 해양 심층 수, 광물 등을 이용하여 피부에 부담을 주지 않으면서(Kwak \& Kim, 2018) 피부 보호, 효능, 재순환 면에서 기존 제품과 차이가 없는 화장품을 개발하는 것을 의미한다(Lim, 2016). 제조과정 면에서는 천연물 분 리 기술 등 관련 기술들의 개발로 피부에 유효한 천연 성분의 추출 이 가능해졌고, 유통 및 포장에서도 환경 친화적이면서 불필요한 쓰 레기를 최소화하기 위한 재활용 가능한 플라스틱류를 사용하고, 코 팅 되지 않은 재활용 종이를 사용한다(Yoo et al., 2004).

지각된 이미지란 소비자들이 제품 또는 서비스를 구매할 때 예 상하는 이익 또는 편익과 관련되는 것의 총칭으로 제품의 품질, 포 장 등과 같은 기능적 이미지, 제품을 소비함으로써 편입될 수 있 는 사회계층 집단 관련 사회적 이미지, 제품의 소비를 통해 느껴 질 수 있는 새로움과 같은 인지적 이미지, 제품 소비를 통해 특정 상황 에 처해 질 것으로 예상되는 상황적 이미지로 구분될 수 있다(Lee, 2015). 이러한 제품에 대한 지각된 이미지는 개인의 주관적인 상황 또는 견해가 작용될 수 있는데, 소비자의 지각된 이미지는 구매한 제품이나 서비스로부터 얻어지는 편익을 의미하고 이는 고객의 행 동을 유발하는 원인이 될 수 있는데 경제적, 경험적인 측면 등 다차 원적인 개념으로 설명될 수 있다(Yoo, 2016).

구매 의도는 소비자가 제품 또는 서비스를 구매하고자 할 때의 구 매의사 결정과정 중 중요한 변수로 실제 화장품 구매 의도와 기업의 성과 측정에 중요한 변수로 고려된다(Jeong et al., 2017). Whang $\&$ Lee (2010)는 구매의도를 소비자의 계획된 미래 행동으로 제품이 나 서비스에 대한 태도가 행동으로 이행될 가능성을 의미하며, 구매 의도가 화장품 구매 의도와 매우 높은 상관관계가 있음을 주장하였 다.

본 연구에서는 고객들의 화장품 기업의 친환경 활동, 지각된 이 미지, 화장품 구매의도의 상관관계를 알아보고자 한다. 이를 통해 화장품 기업의 친환경 활동을 진작시킬 수 있는 방안을 도출함으로 써 고객들로 하여금 친환경 활동을 하는 화장품 기업의 지각 이미지 를 높임으로써 화장품 구매 의도로 이어질 수 있는 방안 마련을 위 한 기초 자료 제공에 본 연구의 의의가 있다.

\section{2. 연구 문제}

본 연구에서는 화장품 기업의 친환경 활동과 고객의 화장품 구매 의도간의 구조적 관계를 파악하고자 한다. 또한, 고객들이 실제로 화장품 구매의도를 가짐에 있어 지각된 이미지의 매개 효과를 검증 하고자 한다.

이를 위해 다음과 같은 연구 문제를 검증하고자 한다.
연구문제 1. 고객에 있어서 화장품 기업의 친환경 활동은 화장품 구매의도에 영향을 미치는가?

연구문제 2. 고객의 화장품에 대한 지각된 이미지는 화장품 기업의 친환경 활동과 화장품 구매의도 간에 매개역할을 하는가?

\section{Methods}

\section{1. 연구 대상 선정 및 자료 수집 기간}

본 연구를 위한 연구 대상자는 서울 및 수도권에 위치한 $\mathrm{F}$ 화장 품 판매점 4 곳의 고객을 대상으로 설문 조사하였다. 본 자료는 총 400 명을 임의로 표집하여 조사하였으며 332 부가 최종적으로 회수 되어 $83.0 \%$ 의 회수율을 나타내었으며 이 중 불성실한 24 부를 제외 하고 총 308 부를 최종 분석에 사용하였다.

조사 기간은 2019년 9월 2일부터 9월 25일까지이었으며, 설문지 작성 요청 전 본 연구자가 직접 연구에 협조하기로 한 $\mathrm{F}$ 화장품 판매 점 점주와 관리자, 직원 및 아르바이트 판매원을 통해 본 설문에 대 한 취지와 작성 요령에 대해 설명하였다. 이후 $\mathrm{F}$ 화장품 판매점 점 주, 관리자, 직원 및 아르바이트 판매원의 설명을 통해 연구의 취지 와 작성 요령을 습득한 연구대상자가 직접 작성토록 한 후 회수하는 방식으로 진행하였다.

\section{2. 조사 도구}

1) 일반적 특성

본 연구에서는 응답자의 일반적 특성으로 성별, 연령, 학력, 거주 지, 결혼상태, 직업, 월평균 가계 소득으로 총 7 문항으로 구성하였 으며 측정방법은 명목 척도를 사용하였다.

\section{2) 친환경 활동}

본 연구에서 독립변수로 사용한 친환경 활동 (eco-friendly activity)이란 인간의 윤택한 삶과 환경 보존이 조화로운 방향으로 함께 이루어질 수 있도록 그 방법을 모색하고 실천함으로써 미래 발 전을 도모해 가는 활동을 의미한다(Kim \& Lee, 2009). 본 연구에서 사용한 친환경 활동의 변수는 원료, 제조과정, 유통, 포장, 재순환으 로 총 5 가지로 정의하였다.

친환경 활동과 관련된 설문지 작성을 위해 $\mathrm{Kim}$ (2009), Lee et al. (2011), Lee \& Lee (2012)의 연구 모형을 참조하여 연구자가 연 구 목적에 맞도록 일부 수정한 문항을 신뢰성, 타당성 분석을 통해 신뢰 수준에 있는 문항을 사용하였다. 문항 내용으로는 5 개 하위 요 인(원료, 제조과정, 유통, 포장, 재순환)의 총 18 개의 문항으로 구성 하였으나 신뢰성 및 타당성 검증을 통해 총 12 개의 문항 5 점 Likert 척도를 사용하였다. 점수가 높을수록 친환경 활동이 높은 것으로 해 석하도록 구성하였다. 
3) 지각된 기업 이미지

본 연구에서 매개변수로 채택한 지각된 기업 이미지(perceived image)란 고객이 기업의 성격 및 특성에 관하여 가지고 있는 고객 의 마음속에 내재된 이미지로써 고객, 언론, 일반 대중 등을 포함한 대부분의 사람들이 해당 기업에 대해 갖는 전반적 인상을 의미할 수 있다(Yoo, 2016). 따라서 지각된 기업 이미지를 기업에 대한 공중의 태도 및 총체적 인상으로 정의 될 수 있다(Lee, 2015). 본 연구에서 의 지각된 이미지는 Lee \& Shin (2015), Yoon \& Yoo (2015)의 연 구 등을 참조로 하여 '고급스러운', '가치 있는', '안전한', '효과 적인' 로 정의하였다. 지각된 이미지 설문을 위해 Kim (2014), Lee et al. (2017), Lee (2015)의 연구 모형을 참조하여 연구자가 연구 목적에 맞도록 일부 수정한 문항을 신뢰성, 타당성 분석을 통해 신뢰 수준 에 있는 문항을 사용하였다. 문항 내용으로는 4 개 하위 요인('고급스 러운', '가치 있는', '안전한', '효과 적인'에 대한 만족)의 총 12 개의 문 항으로 구성하였으나 신뢰성 및 타당성 검증을 통해 총 8개의 문항 5점 Likert 척도를 사용하였다. 점수가 높을수록 지각된 기업 이미 지가 긍정적으로 높은 것으로 해석하도록 구성하였다.
4) 화장품 구매의도

본 연구에서 종속변수로 채택한 화장품 구매의도(purchase intention for cosmetics)란 고객이 미래에 해당 화장품을 구매 및 이용할 가능성이라고 정의 할 수 있다. 화장품 구매의도 설문을 위 해 Vu Thi \& Lee (2014), Lee et al. (2016), Kim et al. (2016b)의 연구 모형을 참조하여 연구자가 연구 목적에 맞도록 일부 수정한 문 항을 신뢰성, 타당성 분석을 통해 신뢰 수준에 있는 문항을 사용하 였다. 문항 내용으로는 3 개 하위 요인(구매의도, 재 구매 의도, 추천 의도)의 총 10 개의 문항으로 구성하였으나, 신뢰성 및 타당성 검증 을 통해 총 7 개의 문항 5 점 Likert 척도를 사용하였다. 점수가 높을 수록 화장품 구매의도 수준이 높은 것으로 해석하도록 구성하였다.

\section{3. 분석방법}

본 연구의 자료는 PASW Statistics by Statistical package for the social sciences (SPSS) 19.0 과 AMOS 19.0을 사용하여 다음 과 같은 방법을 통해 분석되었다. 연구대상자의 일반적 특성은 명 목 척도를 사용하여 조사하였고 친환경 활동, 지각된 이미지, 화

Table 1. General demographic characteristics of the sample

\begin{tabular}{|c|c|c|}
\hline Category & Variables & Percentage (\%) \\
\hline \multirow{2}{*}{ Gender } & Male & $108(35.1)$ \\
\hline & Female & $200(64.9)$ \\
\hline \multirow{5}{*}{ Age } & Under 30 & $119(38.6)$ \\
\hline & $31-40$ & $58(18.8)$ \\
\hline & $41-50$ & $62(20.1)$ \\
\hline & $51-60$ & $62(20.1)$ \\
\hline & Over 61 & $7(2.3)$ \\
\hline \multirow{4}{*}{ Academic background } & High school graduate or less education & $129(41.9)$ \\
\hline & 2 Year college graduate & $79(25.6)$ \\
\hline & University graduate & $75(24.4)$ \\
\hline & Graduate school graduate & $25(8.1)$ \\
\hline \multirow{3}{*}{ Residence } & Country & $10(3.2)$ \\
\hline & Middle-sized \& small cities & 209 (67.9) \\
\hline & Big city & $89(28.9)$ \\
\hline \multirow{2}{*}{ Marital status } & Single/unmarried (divorced \& bereaved) & $181(58.8)$ \\
\hline & Married & $127(41.2)$ \\
\hline \multirow{7}{*}{ Job } & Housewife & $61(19.8)$ \\
\hline & Businessperson & $32(10.4)$ \\
\hline & Professional & $12(3.9)$ \\
\hline & Public official & $20(6.5)$ \\
\hline & Student & $128(41.6)$ \\
\hline & Company staff & $52(16.9)$ \\
\hline & Others & $3(1.0)$ \\
\hline \multirow{5}{*}{ Average monthly family income } & Under $200 \mathrm{KRW}$ & $53(17.2)$ \\
\hline & Over 200-Under 400 KRW & $112(36.4)$ \\
\hline & Over 400-Under $600 \mathrm{KRW}$ & $66(21.4)$ \\
\hline & Over 600-Under 800 KRW & $49(15.9)$ \\
\hline & Over 800 KRW & $28(9.1)$ \\
\hline
\end{tabular}


장품 구매의도의 문항은 리커트 5점 척도를 사용하였다. 구체적 인 분석방법은 유효 표본의 일반적 특성을 파악하기 위해서 빈도분 석, 각 설문 항목의 신뢰성과 타당성 검증은 Cronbach's $\alpha$ 를 사용 하였다. 연구 모형의 적합도 확인을 위해 root mean square error of approximation (RMSEA), root mean square residual (RMR), goodness of fit index (GFI), Normed fit index (NFI), TuckerLewis index (TLI), comparative fit index (CFI) 등의 적합도 지수 를 사용하였으며 측정변수들에 대한 정규성 평가를 위해 요인들의 왜도(Skewness), 첨도(Kurtosis)의 정도를 확인하였다. 또한 각 변 수들 간의 확인적 요인분석을 실시하였고 매개 효과에 대한 통계적 유 의미성 검증을 위하여 소벨 검증(Sobel test)를 실시하였다.

\section{Results}

\section{1. 연구 대상자의 일반적 특성}

연구대상자의 일반적 특성을 살펴본 결과(Table 1) 여성의 경 우 200 명(64.9\%), 남성의 경우 108명(35.1\%)을 나타내었다. 연령 의 경우 30 세 이하가 가장 많아 119 명(38.6\%), 다음으로 41 세-50 세, 51 세-60세가 각각 62 명(20.1\%)을 나타내었다. 학력의 경우, 대 학생이 연구대상자에 다수 포함되어 있어서 고등학교 졸업이 129 명(41.9\%)로 가장 많았고, 다음으로 전문대학 졸업이 79명(25.6\%), 대학교 졸업이 75 명 $(24.4 \%)$ 을 나타내었다. 거주지역의 경우 중소
도시가 가장 많아 209명(67.9\%)이었고, 대도시가 89명(28.9\%)을 나타내었다. 결혼 상태의 경우 미혼(이혼 또는 사별 포함)이 181명 (58.8\%), 기혼이 127 명(41.2\%)을 나타내었다.

직업의 경우 학생이 가장 많아 128 명(41.6\%)를 나타내었고, 다음 으로 가정주부가 61명(19.8\%), 회사원이 52명(16.9\%)을 나타내었 다. 가계의 한 달 소득을 살펴 본 결과 200만원 이상-400만원 미만 이 112 명(36.45)로 가장 많았고, 다음으로 400만원 이상-600만원 미만이 66명(21.4\%)을 나타내었다.

1) 친환경 활동, 화장품 구매의도 및 지각된 이미지 요인의 신뢰성 및 타당성 분석

친환경 활동, 화장품 구매의도 및 지각된 이미지 요인의 차원을 도출하기 위해 베리 맥스 회전 법을 통한 주성분 분석을 실시하였으 며 신뢰성 분석을 위해 각 요인 별로 유통 계수(Cronbach's $\alpha$ )를 계 산하였다(Table 2).

각 요인의 신뢰성 및 타당성 분석결과 친환경 활동(Cronbach's $\alpha=0.748)$, 화장품 구매의도(Cronbach's $\alpha=0.801$, 지각된 이미지 (Cronbach's $\alpha=0.788$ )로 신뢰할 만한 수준에 있다고 볼 수 있다.

\section{2) 변수들의 기술 통계치}

변수들의 기술 통계치를 살펴보면 Table 3 과 같다. 연구 대상자 들이 생각하는 화장품 회사가 시행하고 있는 친환경 활동에 대한 인 식을 조사한 결과 원료는 $4.544 \pm 0.748$ 을 나타내 화장품 기업들

Table 2. Results of reliability and validity analysis on the influential factors affecting eco-friendly activities, purchase intention for cosmetics, and perceived image

\begin{tabular}{lccc}
\hline Variable & Eigen value & Degree of dispersion & Cronbach's alpha $(\alpha)$ \\
Eco-friendly activities & 3.864 & 27.936 & 0.748 \\
Purchase intention for cosmetics & 2.917 & 20.167 & 0.801 \\
Perceived image & 2.304 & 11.209 & 0.788 \\
\hline
\end{tabular}

Note: $\mathrm{KMO}=0.778$; Bartlett gutter certification value $\mathrm{x}^{2}=1394.207$; Total cumulative $=701.207 \%$.

Table 3. Descriptive statistics on influential factors

\begin{tabular}{|c|c|c|c|c|c|}
\hline Category & Variable & Grade average & $\begin{array}{l}\text { Standard } \\
\text { deviation }\end{array}$ & Skewness & Kurtosis \\
\hline \multirow{5}{*}{ Eco-friendly activities } & Base material & 4.544 & 0.748 & -0.142 & -0.048 \\
\hline & Manufacturing process & 3.545 & 0.684 & -0.199 & -0.245 \\
\hline & Distribution & 3.206 & 0.845 & -0.173 & 0.076 \\
\hline & Packaging & 3.113 & 0.772 & -0.627 & -0.107 \\
\hline & Recycling & 4.027 & 0.624 & -0.301 & -0.301 \\
\hline \multirow{4}{*}{ Perceived image } & Luxurious & 3.522 & 0.765 & 0.053 & 0.172 \\
\hline & Valuable & 4.509 & 0.673 & -0.553 & -0.204 \\
\hline & Safe & 4.615 & 0.812 & -0.482 & -0.117 \\
\hline & Effective & 3.847 & 0.768 & 0.301 & 0.190 \\
\hline \multirow{3}{*}{ Purchase intention for cosmetics } & Purchase intention & 4.224 & 0.724 & 0.337 & 0.127 \\
\hline & Repurchase intention & 4.102 & 0.703 & 0.261 & -0.275 \\
\hline & Recommendation intention & 4.325 & 0.638 & 0.227 & -0.294 \\
\hline
\end{tabular}


이 인식하고 있는 화장품 회사의 친환경 활동의 가장 중요한 요소는 자연친화적인 원료로 인식하고 있었다. 제조과정의 경우 $3.545 \pm$ 0.684 를 나타내서 화장품의 제조 과정도 중요한 요인으로 인식하고 있었다. 그러나 유통의 경우 $3.206 \pm 0.845$, 포장은 $3.113 \pm 0.772$ 로 나타나 비교적 낮은 인식을 보이고 있었다.

지각된 이미지의 경우 고급스러운(3.522 \pm 0.765$)$, 가치 있는

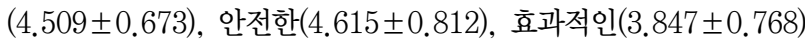
으로 조사되어 친환경 화장품은 가치 있고, 안전한 것으로 생각하 고 있었지만, 고급스러운과 효과적인 항목에서는 다른 항목에 비해 서 다소 낮게 느끼고 있었다. 화장품 구매의도의 경우 구매 의도는 $4.224 \pm 0.724$, 재구매의도의 경우 $4.102 \pm 0.703$, 추천 의도의 경 우 $4.325 \pm 0.638$ 로 나타났다.

\section{3) 측정 모형 분석}

측정변인들이 잠재변인들을 적절히 반영하고 있는지 알아보기 위하여 측정모형분석을 실시하였다. 이를 위해 친환경 활동, 지각된 이미지, 화장품 구매의도의 구조 관계를 확인적 요인분석을 통해 알 아보았다(Table 4). 그 결과 $\chi^{2} / \mathrm{df}=458.367 / 190, \mathrm{RMSEA}=0.129$, $\mathrm{RMR}=0.061, \mathrm{GFI}=0.928, \mathrm{NFI}=0.880, \mathrm{TLI}=0.761, \mathrm{CFI}=0.861$ 로 나타나 모형적합도가 양호한 것으로 나타났다. 또한 연구 모형의 각 변수들 간의 인과관계 분석결과 독립변수에서 친환경 활동의 요인 중 포장에서 $\beta=0.751$ 로 나타나 $p<0.01$ 수준에서 유의미한 영향력 을 가지는 것으로 분석되었고, 친환경 활동의 요인 중 제조과정에서 $\beta=0.504$ 로 나타나 $p<0.001$ 수준에서 유의미한 영향력을 가지는 것 으로 분석되었다. 친환경 활동 요인 중 원료에서 $\beta=0.379$ 로 나타나 $p<0.001$ 수준에서 유의미한 영향력을 가지는 것으로 분석되었으며 친환경 활동 요인 중 재순환에서 $\beta=0.324$ 로 나타나 $p<0.001$ 수준에 서 유의미한 영향력을 가지는 것으로 분석되었다. 매개변수에서 지 각된 이미지 요인 중 '가치 있는'에서 $\beta=0.919$ 로 나타나 $p<0.01$ 수 준에서 유의미한 영향력을 가지는 것으로 분석되었으며, 지각된 이 미지 요인 중 '안전한'에서 $\beta=0.912$ 로 나타나 $p<0.001$ 수준에서 유 의미한 영향력을 가지는 것으로 분석되었으며 지각된 이미지 요인 중 '효과 적인'에서 $\beta=0.804$ 나타나 $p<0.001$ 수준에서 유의미한 영 향력을 가지는 것으로 분석되었다. 종속변수에서 화장품 구매의도 요인 중 추천의도에서 $\beta=0.779$ 로 나타나 $p<0.001$ 수준에서 유의미 한 영향력을 가지는 것으로 분석되었으며 화장품 구매의도 요인 중 재구매의도에서 $\beta=0.681$ 나타나 $p<0.01$ 수준에서 유의미한 영향력 을 가지는 것으로 분석되었다.

4) 구조 모형 분석

(1) 친환경 활동이 화장품 구매의도에 미치는 영향 분석

연구문제 1 인 '화장품 기업의 친환경 활동은 소비자들의 화장품 구매의도에 영향을 미치는가?'을 검증하기 위하여 화장품 회사의 친 환경 활동이 소비자들의 화장품 구매의도에 미치는 영향을 구조 모 형 분석을 통해 알아보았다(Table 5). 각 경로 별 회귀 계수를 살펴 보면 친환경 활동과 화장품 구매의도와의 연관성에서 $\beta=0.102$ 로 나 타나 $p<0.01$ 수준에서 유의미한 영향력을 나타내었다. 이러한 결과 는 소비자들이 느끼는 화장품 회사의 친환경 활동 수준에 따라 화장 품 구매의도의 수준이 달라지는 것을 의미하는데, 화장품 회사의 친 환경 활동 수준이 높을수록 화장품 구매의도 수준이 높아지는 것을

Table 4. Analysis results for the measurement model

\begin{tabular}{|c|c|c|c|c|c|c|c|}
\hline \multicolumn{2}{|c|}{ Observe factor $\longleftarrow$ Potential factor } & $\beta$ & B & S.E & C.R & $p$ & SMC \\
\hline \multirow{5}{*}{ Independence } & Distribution $\leftarrow$ Eco-friendly activities & 0.671 & 1.041 & & & \multirow[b]{2}{*}{ ** } & 0.447 \\
\hline & Packaging $\leftarrow$ Eco-friendly activities & 0.751 & 0.885 & 0.083 & 10.407 & & 0.454 \\
\hline & Manufacturing process $\leftarrow$ Eco-friendly activities & 0.504 & 0.761 & 0.104 & 9.617 & \multirow{2}{*}{$\begin{array}{l}* * * \\
* * *\end{array}$} & 0.279 \\
\hline & Base material $\leftarrow$ Eco-friendly activities & 0.379 & 0.670 & 0.117 & 6.117 & & 0.097 \\
\hline & Recycling Eco-friendly activities & 0.324 & 0.466 & 0.571 & 7.690 & $* * *$ & 0.864 \\
\hline \multirow{4}{*}{ Mediation } & Luxurious $\leftarrow$ Perceived image & 0.884 & 1.846 & & & \multirow{4}{*}{$\begin{array}{l}* * \\
* * * \\
* * *\end{array}$} & 0.745 \\
\hline & Valuable $\leftarrow$ Perceived image & 0.919 & 0.816 & 0.102 & 13.407 & & 0.781 \\
\hline & Safe $\leftarrow$ Perceived image & 0.912 & 0.961 & 0.097 & 11.229 & & 0.801 \\
\hline & Effective $\leftarrow$ Perceived image & 0.804 & 0.672 & 0.17 & 16.301 & & 0.882 \\
\hline \multirow{3}{*}{ Dependence } & Purchase intention $\longleftarrow$ Purchase intention for cosmetics & 0.800 & 1.220 & & & \multirow{3}{*}{$\begin{array}{l}* * * \\
* *\end{array}$} & 0.694 \\
\hline & Recommendation intention $\longleftarrow$ Purchase intention for cosmetics & 0.779 & 0.872 & 0.157 & 19.679 & & 0.667 \\
\hline & Repurchase intention $\leftarrow$ Purchase intention for cosmetics & 0.681 & 0.667 & 0.176 & 19.607 & & 0.679 \\
\hline
\end{tabular}

Note: ${ }^{* *} p<0.01 ;{ }^{* * *} p<0.001 ; \mathrm{X}^{2}=458.367 ; \mathrm{df}=190 ; \mathrm{RMSEA}=0.129 ; \mathrm{RMR}=0.061 ; \mathrm{GFI}=0.928 ; \mathrm{NFI}=0.880 ; \mathrm{TLI}=0.761 ; \mathrm{CFI}=0.861$.

Table 5. Path coefficient of the research model on eco-friendly activities and purchase intention for cosmetics

\begin{tabular}{lccccc}
\hline & $\beta$ & $B$ & S.E. & $p$ & C.R. \\
Eco-friendly activities $\rightarrow$ Purchase intention for cosmetics & 0.102 & 0.885 & 0.047 & 1.967 \\
\hline
\end{tabular}

Note: ${ }^{* *} p<0.01$. 
의미한다.

측정 모형 분석을 통해 잠재 변수와 측정변수간의 관계가 적적함 을 알 수 있었으며, 구조모형분석을 통해 화장품 기업의 친환경 활 동이 소비자들의 화장품 구매의도에 미치는 직접적인 영향과 지각 된 이미지를 통한 매개 효과를 확인하였다.

(2) 지각된 이미지가 친환경 활동과 화장품 구매의도간의 매개 역 할 분석

연구문제 2 인 '지각된 이미지는 화장품 기업의 친환경 활동과 소 비자들의 화장품 구매의도 간에 매개역할을 하는가?'을 검증하기 위 하여 연구대상자들의 친환경 화장품에 대한 지각된 이미지가 화장 품 기업의 친환경 활동과 소비자들의 화장품 구매 의도 간에 미치는 영향을 구조 모형 분석을 통해 알아보았다(Table 6). 각 경로 별 회 귀 계수를 살펴보면 친환경 활동이 지각된 이미지에 미치는 영향은 $\beta=0.375$ ( $p<0.001)$, 친환경 활동이 화장품 구매의도에 미치는 영향 은 $\beta=0.224(p<0.01)$, 지각된 이미지가 화장품 구매의도에 미치는 영향은 $\beta=0.371$ ( $p<0.001)$ 로 나타나 모두 유의미한 영향력을 보여 주었다. 이러한 결과는 화장품 기업의 친환경 활동에 따라 소비자들 의 화장품 구매의도에 미치는 직접적인 영향과 함께 친환경 화장품 에 대한 지각된 이미지가 매개 효과로 나타냄을 보여준다 하겠다.

\section{3) 매개 효과에 대한 소벨 검증}

경로 분석을 통하여 나타난 친환경 활동의 변수들이 화장품 구 매의도에 미치는 영향에서 지각된 이미지의 매개 효과에 대한 통계 적 유의미 성 검증을 위하여 최종적으로 소벨 검증(Sobel test)을 실 시하였다. 분석결과 Table 7과 같이 원료가 지각된 이미지를 매개 로 화장품 구매의도에 미치는 영향의 검증 값이 3.661 ( $p<0.05)$, 제 조과정이 지각된 이미지를 매개로 화장품 구매의도에 미치는 영향
의 검증 값이 $2.983(p<0.05)$, 유통이 지각된 이미지를 매개로 화 장품 구매의도에 미치는 검증 값이 2.010 ( $p<0.05)$, 포장이 지각된 이미지를 매개로 화장품 구매의도에 미치는 검증 값의 경우 0.964 ( $p<0.001)$, 재순환이 지각된 이미지를 매개로 화장품 구매의도에 미 치는 검증 값이 0.825 ( $p<0.001)$ 로 모든 항목에서 지각된 이미지의 매개 효과가 유의미한 것으로 검증되었다.

\section{Discussion}

본 연구는 여성들의 친환경 활동, 지각된 이미지, 화장품 구매의 도의 상관관계를 통해 화장품 기업의 친환경 활동과 고객들의 화장 품 구매의도 간의 구조적 관계를 파악하고자 하였다. 본 연구를 통 해 화장품 기업의 친환경 활동, 지각된 이미지, 고객들의 화장품 구 매의도간의 구조적 관계가 실제로 화장품 구매의도에 미치는 영향 을 파악한 후, 이들 중 지각된 이미지의 매개 효과를 검증하여 화장 품 구매 의도와 관련된 영향요인들을 제시하고자 하였다. 이와 관련 해서 본 연구에서 제시한 연구문제는 '첫째, 고객에 있어서 화장품 기업의 친환경 활동은 화장품 구매의도에 영향을 미치는가? 둘째, 고객의 화장품에 대한 지각된 이미지는 화장품 기업의 친환경 활 동과 화장품 구매의도 간에 매개역할을 하는가?'이다. 이를 위하여 서울 및 수도권에 위치한 $\mathrm{F}$ 화장품 판매점 4곳의 고객 308명의 설 문 자료를 분석에 사용하였으며, 자료는 PASW Statistics by SPSS 19.0 과 $\mathrm{AMOS} 19.0$ 을 통해 분석하였다.

본 연구를 통해 화장품 기업의 친환경 활동을 진작시킬 수 있는 방안을 도출하고 화장품의 지각된 이미지를 통해 소비자들의 화장 품 구매 의도로 이어질 수 있는 방안 마련을 위한 기초 자료 제공에 본 연구의 의의가 있다.

Table 6. Path coefficient of the research model on eco-friendly activities and purchase intention for cosmetics using perceived image as a parameter

\begin{tabular}{|c|c|c|c|c|c|}
\hline & $\beta$ & B & S.E & C.R & $p$ \\
\hline Eco-friendly activities $\rightarrow$ Perceived image & 0.375 & 0.579 & 0.177 & 5.604 & *** \\
\hline Eco-friendly activities $\rightarrow$ Purchase intention for cosmetics & 0.224 & 0.245 & 0.076 & 4.602 & ** \\
\hline Perceived image $\rightarrow$ Purchase intention for cosmetics & 0.371 & 0.102 & 0.081 & 5.794 & *** \\
\hline
\end{tabular}

Note: ${ }^{* *} p<0.01 ;{ }^{* * *} p<0.001$.

Table 7. Sobel verification testing for intermediate paths

\begin{tabular}{lc}
\hline Path & Value \\
Base material $\rightarrow$ Perceived image $\rightarrow$ Purchase intention for cosmetics & $3.661^{*}$ \\
Manufacturing process $\rightarrow$ Perceived image $\rightarrow$ Purchase intention for cosmetics & $2.983^{*}$ \\
Distribution $\rightarrow$ Perceived image $\rightarrow$ Purchase intention for cosmetics & $2.010^{*}$ \\
Packaging $\rightarrow$ Perceived image $\rightarrow$ Purchase intention for cosmetics & $0.964^{* * *}$ \\
Recycling $\rightarrow$ Perceived image $\rightarrow$ Purchase intention for cosmetics & $0.825^{* * *}$ \\
\hline
\end{tabular}

Note: ${ }^{*} p<0.05 ;{ }^{* * *} p<0.001$. 
연구결과는 다음과 같다. 화장품 기업의 친환경 활동에서 유통, 포장, 원료, 제조과정 순으로 높게 인지하고 있었다. 이와 관련하 여 친환경 소재를 이용한 지속 가능한 메이크업을 연구한 선행연구 (Jang \& Yoo, 2012)에서 메이크업 제품의 친환경 소재 원료에 대 한 소비자의 관심 및 이용 요구도가 높다고 주장 하였으며, 유기농 화장품 구매 요인과 포장 디자인의 영향을 연구한 선행연구 $(\mathrm{Lim}$, 2016)에서 자연에서 가져온 원료, 가공 과정, 포장 디자인 및 포장 재는 소비자의 구매 동기에 영향을 미친다고 하였다. 또한 친환경 소재의 에코 뷰티에 관하여 연구한 선행연구(Kim \& Chung, 2013) 에서 친환경 소재의 화장품은 자연 보호와 관련한 의식 있는 소비로 이어진다고 주장하여 본 연구 결과를 지지해 준다.

지각된 이미지의 경우 '고급 스러운'과 '안전한' 측면에서 비교적 높게 인식하고 있었다. 이와 관련하여 메디컬 스킨케어 화장품에 대 한 소비자들의 인식, 이미지, 선호도에 대해 연구한 선행연구(Park et al., 2015)에서 메디컬 스킨케어 화장품에 대한 소비자의 선호도 요인 중 안정성을 중요한 요인으로 지적하였고, 한·중·일 3 개국 9 개 화장품 브랜드에 대한 기호학적 분석을 중심으로 화장품 브랜드에 대한 브랜드 이이덴티티와 브랜드 이미지 인식에 대한 연구를 진행 한 선행연구(Jeon \& Lee, 2015)에서 화장품 브랜드 아이덴티티와 브랜드 이미지 인식 중 소비자들은 화장품 브랜드의 인지도, 고가, 효용성 요인이 구매 동기와 유의미한 상관관계를 갖는다고 하였다. 또한 한류가 베트남 시장에서 한국 이미지와 화장품 브랜드 이미지 에 미치는 영향을 연구한 선행연구(Lee, 2015)에서 한국산 화장품 브랜드 이미지는 효능성, 사치성 요인에서 높은 인지도를 갖는다고 하여 본 연구 결과를 지지해 준다.

친환경 활동, 지각된 이미지, 구매 행동의 구조 관계를 확인적 요 인분석을 통해 각 변수들간의 인과 관계 분석결과 친환경 활동은 포 장, 제조과정, 원료, 재순환에서 유의미한 영향력을 가지고 있는 것 으로 분석되었다. 지각된 이미지는 가치 있는, 안전한, 효과적인에 서 유의미한 영향력을 가지고 있었으며, 화장품 구매의도에서는 추 천 의도, 재구매의도에서 유의미한 영향력을 가지고 있는 것으로 분 석되었다.

연구문제 1 인 '화장품 기업의 친환경 활동은 소비자들의 화장품 구매의도에 영향을 미치는가?'을 검증한 결과 친환경 활동과 화장품 구매의도사이에 유의미한 영향력을 나타내 소비자들이 느끼는 화장 품 회사의 친환경 활동 수준에 따라 화장품 구매의도의 수준이 달라 지는 것으로 나타났다. 이는 화장품 회사의 친환경 활동 수준이 높 을수록 화장품 구매의도 수준이 높아지는 것을 의미한다. 이와 관련 하여 코리아나 화장품 기업의 친환경 경영이 실적과의 연관성을 밝 히고, 미래 과제를 제시한 선행연구(Yoo et al., 2004)에서 코리아나 화장품 기업의 친환경 경영은 소비자들에게 코리아나 화장품 기업 의 친환경 브랜드 이미지를 상승시켰으며 이는 경영 성과의 상승으 로 이어졌다고 주장하였다. 웰빙 사회의 소비자 가치 지향, 지각된 가치, 브랜드 선호도가 친환경 화장품의 구매의도에 영향을 미친다
고 주장한 선행연구(Kim \& Lee, 2009)에서 웰빙 사회의 소비자들 의 소비자 가치 지향의 변화는 지각된 가치 변화를 가져왔고 기존의 화장품 선택 시 중요한 요인이었던 가격요인보다 가치 중심의 브랜 드 선호도로 바뀌었다고 주장하였다. 또한 화장품 기업의 친환경 활 동은 화장품 기업의 브랜드 자산에 영향을 미치고 이는 소비자들의 긍정적인 평가로 이어져 경영성과에 긍정적인 영향을 준다고 주장 한 선행연구(Lee \& Lee, 2012)의 연구 결과들은 본 연구 결과를 지 지해 준다.

연구문제 2 인 '지각된 이미지는 화장품 기업의 친환경 활동과 소 비자들의 화장품 구매의도 간에 매개역할을 하는가?'을 검증한 결과 화장품 기업의 친환경 활동에 따라 소비자들의 화장품 구매의도에 미치는 직접적인 영향과 함께 친환경 화장품에 대한 지각된 이미지 가 매개 효과로 나타났다. 이와 관련하여 웰빙 소비자의 라이프 스 타일에 따른 친환경 화장품 구매 행동 세분화 과정을 연구한 선행연 구(Kim, 2009)에서 웰빙 소비 성향 라이프 스타일을 갖는 소비자들 은 친환경 화장품 브랜드에 대한 친환경 이미지를 형성하고 이는 구 매 의도로 이어진다고 주장하여 본 연구 결과를 지지한다.

화장품 기업의 친환경 활동의 변수들이 화장품 구매의도에 미치 는 영향에서 지각된 이미지의 매개 효과에 대한 검증 결과 원료는 지각된 이미지를 매개로 화장품 구매의도, 제조과정은 지각된 이미 지를 매개로 화장품 구매의도, 유통은 지각된 이미지를 매개로 화장 품 구매의도, 포장은 지각된 이미지를 매개로 화장품 구매의도, 재 순환은 지각된 이미지를 매개로 화장품 구매의도에서 유의미한 영 향력을 확인하여 지각된 이미지의 매개 효과가 유의미한 것으로 검 증되었다.

이상의 연구결과를 토대로 다음과 같은 점을 제안하고자 한다.

본 연구는 소비자들의 트렌드가 웰빙, 친환경, 로하스 중심으로 변화되고 있는 시점에서 화장품 기업에게 의미 있는 시사점을 제공 해 주고 있다. 연구를 통해 화장품 기업의 친환경 활동은 지각된 이 미지에 영향을 주고 이는 화장품 구매 의도로 이어진다. 소비자들의 친환경에 대한 인식은 날로 변화되고 있다. 소비자들은 최근의 환경 문제에 대해 관심이 높으며, 환경 파괴에 대한 우려가 높아짐에 따 라 친환경적 소비 성향을 나타내는 예가 많다. 이러한 변화는 친환 경 화장품에 대해서는 안전하며 조금 비싸더라도 환경 보존을 위해 친환경 제품을 구매한다는 점을 유추할 수 있다. 이와 같은 소비자 인식의 변화는 화장품 기업의 환경을 위한 적극적인 노력을 요구하 고 있다. 심플한 제품 포장, 친환경 소재를 활용한 제품 설명, 재활 용 소재를 이용한 매장 인테리어, 제품 포장 시 에코 백 사용, 친환 경 캠페인 또는 이벤트 활용, 친환경 원료 개발 등 다각도의 노력과 실천이 요구된다. 이와 관련하여 중. 노년 여성을 대상으로 생활방 식에 따른 한방 화장품 구매 행동과 태도와의 관계를 연구한 선행연 구(Whang \& Lee, 2010)에서 웰빙 중시, 미래 세대에 대한 책임감, 친환경 관심 수준이 높은 중. 노년 여성의 경우 한방 화장품 구매 행 동 및 태도 수준이 높은 것으로 조사되었고, 웰빙 라이프 스타일이 
자연주의 화장품의 지각된 가치와 구매의도에 미치는 영향을 연구 한 선행연구(Oh et al., 2010)에서 웰빙 라이프 스타일 수준이 높은 소비자의 경우 자연주의 화장품에 대한 지각된 가치 수준이 높으며 이에 따라 자연주의 화장품을 구매, 추천하고자 하는 의도가 높다고 하였다. 또한 화장품 전 성분 표시 인식이 친환경 화장품 구매의도 에 미치는 영향을 연구한 선행연구(Kim \& Han, 2010)에서 화장품 전 성분 표시에 대한 관심도가 높고 이해 수준이 높은 소비자일수록 친환경 화장품에 대한 관심도, 구매의도가 높다고 주장하여 본 연구 결과를 지지하고 있다.

또한, 친환경 활동을 하는 화장품 기업에 대한 지각된 이미지는 긍정적이라는 것을 알 수 있으며, 긍정적인 지각된 이미지는 제품 구매로 이어짐을 알 수 있었다. 이를 통해 화장품 기업과 소비자들 의 친환경 커뮤니케이션이 중요하다 할 수 있겠다. 이를 위해서는 기업의 친환경 철학, 윤리 경영과 같이 제품 관련 요인을 넘어선 높 은 가치를 필요로 한다. 이러한 기업의 노력은 사회의 지속가능성에 기여하고, 소비자들의 친환경 인식 및 태도 변화에 부응하며, 소비 자들의 친환경 화장품 구매로 이어져 궁극적으로 화장품 기업의 수 익창출과 자연 보존에 기여 할 수 있을 것이다. 이와 관련하여 웰빙 사회의 소비자 가치 지향, 지각된 가치, 브랜드 선호도를 연구한 선 행연구(Kim \& Lee, 2009)에서 웰빙과 관련한 소비자 가치 지향 수 준이 높고, 환경의 중요성에 대한 지각된 가치 수준이 높을수록 친 환경 브랜드에 대한 관심도가 높고 이는 소비 행태로 이어진다고 하 였다. 친환경 화장품 잡지 광고의 조형적 특성에 관한 연구를 통해 소비자들의 인식의 연관성을 연구한 선행연구(Lee et al., 2011)에 서 친환경 화장품 잡지 광고를 통한 브랜드 가치 제고는 소비자들의 해당 제품에 대한 긍정적인 인식, 이타적인 인식과 상관관계를 갖는 다고 하였다. 또한 화장품 기업의 친환경 활동이 브랜드 자산에 미 치는 영향을 연구한 선행연구(Lee \& Lee, 2012)에서 화장품 기업의 광고, 캠페인, 포장, 스토어 이미지, 점원의 친환경 의상은 브랜드 자산과 상관관계가 있으며, 소비자들의 기업에 대한 긍정적인 친환 경 이미지로 연결될 수 있다고 하여 본 연구 결과를 지지한다.

\section{Conclusion}

소비자들의 환경에 대한 관심도, 친환경 소비 행동, 직접적인 친 환경 활동은 화장품 기업의 변화를 유도하고 있다. 해외 화장품 기 업들은 오랜 역사 동안 체계적인 정책 기조 하에 이벤트 성이 아닌 장기간의 일관된 기업 컨셉으로 환경 보호와 관련한 다양한 프로젝 트를 진행하고 있으며 이를 통해 기업의 친환경 이미지를 확고히 하 고 있다. 이에 비해 비교적 짧은 친환경 역사를 가졌지만 최근 친환 경 경영 전략을 표방하고 마케팅 활동을 하는 국내 화장품 기업도 증가하고 있는 추세이다. 친환경 활동을 하는 기업에 대한 인식은 긍정적이며, 이는 구매 의도로 이어질 수 있으므로 기업은 친환경
기업의 이미지를 구축하기 위해 다양한 친환경 활동을 개발하고, 이 를 기업의 경영이념에 삽입하여 지속적으로 실천하여야 한다. 이를 통한 소비자들의 신뢰를 바탕으로 지속 가능한 경영이 유지되고 기 업의 꾸준한 수익 추구에 기여할 수 있을 것이다.

본 연구는 다음과 같은 한계점을 갖는다. 첫째, 표본의 대표성 문 제이다. 본 연구에서 표본으로 선정된 소비자는 서울 및 수도권에 거주하고 있으며, 특정 화장품 판매점을 이용한 고객으로 한정하였 음을 감안할 때 본 연구 결과를 일반화하기에는 다소 무리가 있다고 생각된다. 둘째, 화장품 기업의 친환경 활동은 매우 다양할 수 있으 나 본 연구에서는 그 중 일부로 한정하였다는 점이다. 그러나 그럼 에도 불구하고 본 연구결과가 기존 선행 연구결과와 동일한 결과를 보였고, 화장품 기업의 친환경 활동을 통한 화장품 구매의도를 높일 수 있는 방안을 모색해 봄은 의의가 있다 할 수 있다. 따라서 본 연 구는 추후 화장품 기업의 친환경 활동을 독려할 수 있는 토대를 마 련하고, 이를 통해 해당 화장품 기업의 긍정적인 이미지 구축을 통 한 화장품 구매 의도로 이어질 수 있는 방안 마련이 가능할 것으로 사료되며 이는 향후 화장품 기업의 친환경 활동에 활용이 가능할 것 으로 사료된다.

\section{Author's contribution}

YJO designed, analyzed data, and wrote the manuscript.

\section{Author details}

Yoo-Jin Oh (Graduate student), Department of Health and Beauty, Dongduk Women's University, 60, 13-gil, Hwarang-ro, Seungbuk-gu, Seoul 02748, Korea.

\section{References}

Jang YY, Yoo TS. Sustainable makeup design using environment-friendly materials. Journal of Korea Design Forum, 37: 199-210, 2012.

Jeon HY, Li Y. A study on Chinese consumers' perception for brand identity \& brand image of cosmetic brands: through semiotic analysis of Korean, Chinese and Japanese cosmetic brands. Semiotic Inquiry, 44: 255292, 2015.

Jeong MJ, Jin BH, Yang HS. The influences of Korean wave and product image on online purchase intention for Korean cosmetics in Vietnam. Journal of Consumption Culture, 20: 163-181, 2017.

Jeong $\mathrm{M}$, Jin B, Yang $\mathrm{H}$. The influences of Korean wave and product image on online purchase intention for Korean 
cosmetics in Vietnam. Journal of Consumption Culture, 20: 163-181, 2017.

Jeong $\mathrm{YH}$, Yoo MJ. Anti-oxidative and anti-inflammatory effects of codonopsis lanceolata skin extracts. Asian Journal of Beauty and Cosmetology, 16: 347-357, 2018.

Kim B, Jeon D, Im D. Antecedents of repurchasing intention and recommendation intention in a cosmetic product context: focused on females in their twenties. The Journal of Korea Contents Association, 16: 276-285, $2016 a$.

Kim R, Jin D, Park JM. The effects of localized brand name, image of Korean celebrity advertising model and image of country-of-origin on Chinese consumers' choice behaviors. Korean Corporation Management Review, 67: 1-23, 2016b.

Kim HJ, Lee HZ. The effect of the well-being consumer value orientations, the perceived value and brand preference on purchase intention of the environment-friendly cosmetic. Journal of the Korean Society of Cosmetology, 15: 327-341, 2009.

Kim HJ. A study of segmentation on environment-friendly cosmetic purchasing behavior according to well-being consumer' lifestyle. Journal of the Korea Design Society, 5: 193-207, 2009.

Kim JY. A study on design for enhancing brand awareness of color cosmetics brands. A Journal of Brand Design Association of Korea, 12: 311-320, 2014.

Kim KW, Choi YH, Kim BR, Kim YY, Seong RS, Han MH, Kim KA, Choi MJ, Jeong YK. Determination of anti-oxidative and whitening effects of complex extracts obtained from sprout Panax ginseng C.A. meyer and Cassia nomame (sieb.) honda on skin. Asian Journal of Beauty and Cosmetology, 16: 309-320, 2018.

Kim MY, Chung JY. The research on the environment-friendly echo beauty: focused on the mask pack brand. $A$ Journal of Brand Design Association of Korea, 11: 237250, 2013.

Kim SK, Han CJ. Influences of perceptions of the full ingredient labeling of cosmetic products on the purchase intentions of environment-friendly cosmetic products: with a focus on the theory of planned behavior. Asian Journal of Beauty and Cosmetology, 8: 1-15, 2010.

Kwak JS, Kim CD. Persicaria thunbergii extract as a physiologically active cosmetic ingredient. Asian Journal of Beauty and Cosmetology, 16: 381-392, 2018.

Lee CW, Sang M, Cho Y. A research on the intentions to purchase the cosmetic products on the part of the Chinese consumers resulting from the Korean wave perceptions: focused on the corporations and the national image. Northeast Asia Tourism Research, 12: 99-120, 2016.

Lee JH. A study on Korea country image and cosmetics brand image in Vietnam market by the Korean wave. International Commerce and Information Review, 17: 73-91, 2015.

Lee KH, Je GY, Kim ML. Formative characteristics of magazine advertisement in eco-friendly cosmetics. The Research Journal of the Costume Culture, 19: 150-162, 2011.

Lee KS, Lee HS. Influence of the cosmetic company's ecofriendly activities on brand equity. Journal of Beauty Art Management, 6: 267-274, 2012.

Lee SE. Effects of visual images of low-cost cosmetics on consumer types and their behaviors. Asian Journal of Beauty and Cosmetology, 14: 30-41, 2016.

Lee SJ, Lee NH, Yang YJ, Jung YJ. A study of the effects a study on the correlation between cosmetics brand image and fragrance recognized by consumers: focusing on 20s' consumers. The International Society of Nail Beauty Design, 5: 53-68, 2017.

Lee YJ, Shin SY. Visual image evaluation criteria of domestic and international cosmetics brands. Journal of the Korean Society of Design Culture, 21: 537-550, 2015.

Lim BW. A study on factors of purchasing decisions and colors of package design into organic cosmetics. Journal of the Korean Society of Illustration Research, 47: 7180, 2016.

Oh MH, Park HJ, Lee SH, Park SY. The effect of well-being lifestyle on perceived value and purchase intention of naturalistic cosmetics. Asian Journal of Beauty and Cosmetology, 8: 175-190, 2010.

Park JH, Song YS, Lee KK. Perception, image and preference of medical skin care cosmetics. Journal of Naturopathy, 4: 22-30, 2015.

Vu Thi T, Lee JH. An empirical on the Korean cosmetics satisfaction of the Vietnamese consumer and repurchase intention. Journal of International Commerce 
Impact of a Cosmetic Company's Eco-Friendly Activity on Purchase Intention

and Information, 16: 227-243, 2014.

Whang WK, Lee YA. A study on the oriental cosmetics purchasing behavior and attitudes according to middle, elderly women's lifestyle. Asian Journal of Beauty and Cosmetology, 8: 53-62, 2010.

Yoo CJ, Kwon IH, Lee DH. Koreana's performance through environment-oriented management and future task. Journal of Consumption Culture, 7: 107-120. 2004.

Yoo HK. Images of K-beauty and Korean cosmetic brands perceived by Vietnamese women. A Journal of Brand Design Association of Korea, 14: 219-230, 2016.

Yoon JY, Yoo TS. Analysis of perspectives on the image of south Korea as a nation, attitudes toward Korean cosmetics, and purchasing intentions among Chinese female undergraduate students: focused on Beijing, Shanghai, Guangzhou. Korea Society of Design Trend, 49: 97-107, 2015. 


\section{화장품 기업의 친환경활동이 지각된 이미지를 매개로 화장품 구매의도에 미치는 영향}

오유진

동덕여자대학교 보건향장학과, 서울, 한국

목적: 본 연구는 화장품 판매점의 고객을 대상으로 화장품 기업의 친환경 활동이 지각된 이미지를 매개로 화장품 구매의도에 미치 는 영향을 알아보기 위해 진행되었다. 방법: 본 연구를 수행하기 위해 2019년 9월, 화장품 판매점 4곳의 고객을 대상으로 설문 조 사하였다. 총 308 부가 분석에 사용되었다. 결과: 소벨 검증결과 원료 는 지각된 이미지를 매개로 한 화장품 구매의도의 검증 값이 3.661 ( $p<0.05)$, 제조과정은 지각된 이미지를 매개로 한 화장품 구매의도의 경우 2.983 ( $p<0.05)$, 유통의 경우 지각된 이미지를 매 개로 한 화장품 구매 의도는 2.010 ( $p<0.05)$, 포장의 경우 지각된 이미지를 매개로 한 화장품 구매의도의 경우 $0.964(p<0.001)$, 재 순환의 경우 지각된 이미지를 매개로 한 화장품 구매의도의 검증 값이 0.825 ( $p<0.001)$ 로 모든 항목에서 지각된 이미지의 매개 효 과가 유의미한 것으로 검증되었다. 결론: 기업은 친환경 기업의 이미지를 구축하기 위해 다양한 친환경 활동을 개발하고, 이를 기업 의 경영이념에 삽입하여 지속적으로 실천하여야 한다.

핵심어: 영향요인, 화장품, 친환경 활동, 지각된 의미지, 구매의도

\section{참고문헌}

곽정심, 김춘득. 화장품 소재로서 고마리 추출물의 생리활성. 아시안뷰티화장품학술지, 16: 381-392, 2018.

김건우, 최윤희, 김병록, 김영욱, 성락선, 한민희, 김경애, 최민주, 정용기. 새싹인삼과 차풀 복합추출물의 피부 항산화 및 미백효과. 아시안뷰티화장품학술지, 16: 309-320, 2018.

김미영, 정재윤. 친환경 소재의 에코뷰티에 관한 연구. 브랜드디자인학연구, 11: 237-250, 2013.

김병수, 전두리, 임동. 화장품 재구매의도와 추천 의도에 영향을 미치는 요인. 한국콘텐츠학회논문지, $16: 276-285$, 2016a.

김보영, 정근, 박종민. Brand name의 현지화, 광고모델 이미지 및 원산지 이미지가 중국소비자의 한국산 화장품 제품평 가에 미치는 영향. 기업경영연구, $67: 1-23,2016 \mathrm{~b}$.

김선경, 한채정. 화장품 전 성분 표시 인식이 친환경 화장품 구매의도에 미치는 영향: 계획행동이론을 중심으로. 아시안뷰 티화장품학술지, 8: 1- $15,2010$.

김진아, 오윤경. 온라인전용 브랜드 화장품의 구매행태와 만족도. 아시안뷰티화장품학술지, 16: 32-41, 2018.

김진영. 색조화장품의 브랜드 이미지 강화를 위한 디자인 연구. 브랜드디자인학연구, $12: 311-320,2014$.

김효진, 이혜주. 웰빙 사회의 소비자 가치지향, 지각된 가치, 브랜드 선호도가 친환경 화장품 구매의도에 미치는 영향. 한 국미용학회지, 15: 327-341, 2009.

김효진. 웰빙 소비자의 라이프스타일에 따른 친환경 화장품 구매행동 세분화 연구. 코리아뷰티디자인학회지, 5: 193207, 2009.

박지형, 송연숙, 이근광. Medical Skin Care 화장품에 대한 인식, 이미지 및 선호 정도. 한국자연치유학회지, 4: 22-30, 2015.

부띠따오, 이제홍. 베트남 소비자의 한국화장품 구매 만족과 재구매 의도에 관한 실증분석. 통상정보연구, 16: 227-243, 2014.

오만호, 박현정, 이상환, 박수용. 웰빙 라이프스타일이 자연주의 화장품의 지각된 가치와 구매의도에 미치는 영향. 아시안 뷰티화장품학술지, 8: 175-190, 2010. 
유창조, 권익현, 이두희. 친환경 경영을 통한 코리아나의 실적과 미래 과제. 소비문화연구, 7: 107-120. 2004. 유혜경. 베트남 여성들이 지각하는 K-beauty와 한국화장품 브랜드 이미지. 브랜드디자인학연구, 14: 219-230, 2016. 윤지영, 유태순. 중국 여대생의 한국국가이미지, 화장품이미지, 화장품태도, 구매의도와의 관계: 베이징·상하이·광저우 지 역을 중심으로. 한국디자인포럼, 49: 97-107, 2015.

이경숙, 이현숙. 화장품 기업의 친환경 활동이 브랜드 자산에 미치는 영향. 미용예술경영연구, 6: 267-274, 2012. 이경희, 제기연, 김명리. 친환경 화장품 잡지 광고의 조형적 특성에 관한 연구. 복식문화연구, 19: 150-162, 2011. 이상은. 저가화장품 시각적 이미지가 소비자유형과 구매행동에 미치는 영향. 아시안뷰티화장품학술지, 14: 30-41, 2016. 이서진, 이나현, 양연정, 정연자. 소비자들이 인식하는 화장품 브랜드 이미지와 향과의 상관성 연구: 20 대 소비자 중심으 로. 한국네일미용학회지, 5: 53-68, 2017.

이유정, 신세영. 국내외 화장품 브랜드의 시각적 이미지 평가기준. 한국디자인문화학회지, 21: 537-550, 2015. 이재홍. 한류가 베트남 시장에서 한국 이미지와 화장품 브랜드 이미지에 관한 연구. 통상정보연구, 17: 73-91, 2015. 이철우, 상맹, 초연. 중국 소비자의 한류지각과 화장품 구매의도에 관한 연구: 기업과 국가 이미지를 중심으로. 동북아관광 연구, 12: 99-120, 2016. 임병우. 유기농 화장품 구매 요인과 포장디자인 색채에 관한 연구. 일러스트레이션 포럼, 47: 71-80, 2016. 장윤영, 유태순. 친환경 소재를 이용한 지속가능한 메이크업 디자인. 한국디자인포럼, 37 199-210, 2012. 전형연, 이원. 한. 중. 일 3 개국 화장품 브랜드에 대한 브랜드 아이덴티티와 브랜드 이미지 인식연구-3개국 9 개 브랜드에 대한 기호학적 분석을 중심으로. 기호학연구, 44: 255-292, 2015.

정민지, 진병호, 양희순. 한류 및 제품이미지가 한국 화장품의 온라인 구매의도에 미치는 영향: 베트남 소비자를 대상으로. 소비문화연구, 20: 163-181, 2017.

정윤희, 유민정. 더덕 껍질 추출물의 항산화 및 항염증 효과. 아시안뷰티화장품학술지, 16:347-357, 2018. 황완균, 이영애. 중. 노년 여성의 생활방식에 따른 한방 화장품 구매행동과 태도. 아시안뷰티화장품학술지, 8: 53-62, 2010. 


\section{中文摘要}

\section{化妆品企业环保活动通过知觉形象的中介效应对消费者购买意愿的影响}

吳有珍

同德女子大学保健香妆学科，首尔，韩国

目的：本研究旨在通过知觉形象的中介效应，探讨化妆品公司环保活动对消费者购买意愿的影响。方法: 本文采 用文献资料法和问卷调查法来进行研究。2019年9月，在首尔和京畿区的四家化妆品商店进行了随机抽样。在 400份问卷中，308份采用社会科学统计软件包（SPSS 19.0）和amos19.0进行统计分析。测量频率、信度、 效度, 并进行近似均方根误差、均方根残差、拟合优度指数、标准拟合指数、塔克-刘易斯指数、比较拟合指 数和Sobel检验来进行数据分析。Cronbach的 $\alpha$ 值分别为 0.748 和 0.801 。结果：中间路径的Sobel检验验证结 果为：影响消费者购买意愿的基础材料对感知形象的中介作用为 $3.661 （ p<0.05 ）$ ，影响消费者购买意愿的制 造过程对感知形象的中介作用为 $2.983(p<0.05)$ ，在流通方面，以感知形象为媒介的化妆品购买意图为 2.10 $(p<0.05)$ ，包装方面以感知形象为媒介的化妆品购买意图为0.964（ $p<0.001 ） ，$ 再循环的情况下，以感知 形象为媒介的化妆品购买意图的验证值为 $0.825(p<0.001)$, 证明了所有项目中, 感知形象的媒介效果是显著 的。结论: 化妆品企业应坚持绿色环保活动, 树立消费者形象。有助于提高消费者的环保形象, 增加消费者对化 妆品的购买意愿。

关键词: 影响因素、化妆品、环保活动、感知形象、购买意向 
